\title{
Mesenchymal Stem Cells for Treatment of Myocardial Infarction
}

\author{
Il-Kwon Ko, Byung-Soo Kim \\ Department of Bioengineering, Hanyang University, Seoul, Korea
}

Cardiovascular diseases including myocardial infarction are one of the major causes of adult mortality. Several treatments such as pharmacological therapy and heart transplantation have been used for the diseases, but the treatments have drawbacks. Therefore, cell-based myocardial therapies have received proper medical attention. Bone marrow stem cell (BMSC) including mesenchymal stem cell (MSC) and hematopoietic stem cell (HSC) is a potential source for cell therapy for heart diseases due to the ability of BMSC to differentiate into cell in cardiac tissue including cardiomyocyte and vascular endothelial cell. This article reviews the use of BMSCs for cardiovascular disease and the differentiation of BMSCs into cardiaomyocytes.

Keywords: Mesenchymal stem cell, Myocardial infarction, Differentiation, Cardiomyocyte

\section{Introduction}

Ischemic heart disease had an increase in mortality four times over the past ten years in Korea (1). Change in Korean traditional eating habits to western eating habits, lack of exercise, and increased life span are thought to increase cardiovascular diseases including myocardial infarction. Treatments for heart disease include pharmacological therapy, surgical therapy, and heart transplantation. However, these methods are suboptimal and insufficient donors of heart organ for heart transplantation limit the therapy. Cell therapy is currently being investigated as an alternative treatment modality for patients with heart diseases. Cell therapy for heart failure has the potential to restore cardiac functions by enhancing angiogenesis, regenerating viable myocardium, and protecting myocardium from cell death. Bone marrow stem cells (BMSCs) present an attractive source of cells for the cell therapy (2).

\footnotetext{
Accepted for publication October 2, 2008

Correspondence to Byung-Soo Kim

Department of Bioengineering, Hanyang University, 17, Haengdang-

dong, Seongdong-gu, Seoul 133-791, Korea

Tel: +82-2-2290-0491, Fax: +82-2-2291-0838

E-mail: bskim@hanyang.ac.kr
}

\section{Use of BMSCs for myocardial infarction}

Animal studies have shown that BMSC mobilization is effective in cardiovascular tissue regeneration. In a study, lineage-negative (Lin-) bone marrow cells from transgenic mice expressing enhanced green fluorescent protein were injected in the heart wall bordering infarct. As a result, newly formed myocardium occupied $68 \%$ of the infarcted portion of the ventricle. The regenerated tissue comprised proliferating myocytes and vascular structures. These results indicate that locally delivered bone marrow cells can generate myocardium and improve the outcome of coronary artery disease (3).

Soluble factors including growth factors and cytokine are important factors for BMSC differentiation. In a study, bone marrow cells from adult rats were cultured in a conventional cell culture medium (control) and the medium with 5-azacytidine. Myotubules stained positively for troponin I and myosin heavy chain were observed only in the cells cultured with the medium with 5-azacytidine. After myocardial infarction, fresh bone marrow cells, cultured bone marrow cells, 5-azacytidine-induced bone marrow cells, and medium were injected into the scar. As a result, cardiomyocyte-specific markers, including myosin heavy chain and troponin I, were observed in the scar tissue of the groups of bone marrow cell transplantation. However, only the 5-azacytidine-treated bone marrow cell group 
showed systolic and developed pressures that were higher than those of the control hearts. Angiogenesis in the scar tissue was also found in the groups of bone marrow cell transplantation (4). These results suggest that 5-azacytidine induces bone marrow cells to differentiate into cardiomyocytes.

Stem cell mobilization from bone marrow is an easy treatment, and has the least risk for myocardial infarction treatment. Mechanism of stem cell mobilization has been used for collecting stem cells for autologous or allogenic stem cell transplantation. To mobilize stem cell, granulocyte colony stimulating factor (G-CSF) or granulocyte macrophage colony stimulating factor (GM-CSF) is administered alone or in combination, and sometimes administered with chemotherapy. The mechanism of mobilization is not still clear. It may involve upregulation of proteases and a secondary decrease in stromal cell-derived factor-1 (SDF-1) concentration in bone marrow (5). The event causes to cut linkage between stromal cells and stem cells, and hematopoietic stem cells (HSCs) are released into blood stream and circulate in the body. Some HSCs participate in regeneration of myocardium in infarction region (5). This method has been adopted for clinical purpose due to the easy availability of mobilized stem cells. The clinical trails have shown the realizable possibility and safety of mobilization (6).

The FIRSTLINE-AMI (the Front-Integrated Revascularization and Stem Cell Liberation in Evolving Acute Myocardial Infarction by Granulocyte Colony-Stimulating Factor) trial showed that mobilization of CD34-positive MNCs with G-CSF may offer a great strategy for improvement in ventricular function and prevention of left ventricular remodeling after acute myocardial infarction (7). G-CSF stimulation led to sustained mobilization of CD34positive MNCs. CD34-positive MNC mobilization led to enhanced resting wall thickening in the infarction region (7). Another study showed increase in collateral flow in patients with coronary artery disease after GM-CSF treatment. In twenty one patients with extensive coronary artery disease who were not eligible for coronary artery bypass surgery, the effect of GM-CSF on quantitatively assessed collateral flow was tested in a randomized, double-blind, placebo-controlled fashion. In a consequence, the clinical study documented that the use of GM-CSF to improve collateral flow has an effect in a short-term administration protocol (8).

BOOST (Bone marrow transfer to enhance ST-elevation infarct regeneration) trial documented that intracoronary transfer of autologous bone marrow cells can improve left ventricular ejection fraction (LVEF) at 6 month follow-up
(9). The patients were randomly assigned to either a control group that received optimum postinfarction medical treatment or bone marrow cell group that received optimum medical treatment and intracoronary transfer of autologous bone marrow cells. After 6 months, the bone marrow cell group increased LVEF compared to the control group. Therefore, the trial shows that intracoronary transfer of autologous bone marrow cells promotes improvement of left ventricular systolic function in patients after acute myocardial infarction (9). Likewise, REPAIR-AMI (The Reinfusion of Enriched Progenitor Cells and Infarct Remodeling in Acute Myocardial Infarction) trial showed an improvement. Patients with acute myocardial infarction were randomly assigned to receive an intracoronary infusion of progenitor cells derived from bone marrow or placebo medium into the infarct artery. The improvement in the LVEF was significantly greater in the bone marrow cell treatment group than in the placebo group (10).

\section{Problems of use of BMSCs for myocardiac infarction}

MSCs have a potential to differentiate into undesired tissues, including bone and fat. Therefore, methods to prevent differentiation of implanted MSCs towards unwanted cells are required. In a study, encapsulated structures were found in the infarcted area of a large fraction of heart after injecting MSCs. The structures contained calcifications or ossifications (11). Another study also showed that transplantation of unfractionated bone marrow cells into acutely infarcted myocardium may induce significant intramyocardial calcification (12). These results suggest that whole bone marrow may have some factors that induce bone formation in hearts. MSCs also have potential to differentiate into adipocytes. This event has not been reported in administration into human hearts yet. In a case of experimental renal diseases, adipogenesis at site of MSC application was found (13). There are some methods that prevent differentiation of injected MSCs into unwanted cell types. Ex vivo or in situ stimulation of MSC differentiation with various factors or genes would increase therapeutic potential of stem cells, while limiting their differentiation into unwanted cell types (14).

MSCs expanded in culture for long periods may have a probability of genetic instability and malignant transformation. A recent study analyzed the genetic stability of MSCs derived from human adipose tissue and cultured in a long-term. The cultured cells entered an accelerated growth rate. These cells also contained chromosomal ab- 
normalities (15). In a study on murine MSCs, a number of abnormalities were found in cultured primary bone marrow-derived MSCs, and sarcoma evolved from the MSC culture (16). However, there is a significant difference between human and murine bone marrow-derived MSCs. Unlike murine cells, human cells can stop growing after a certain number of passages. However, under stressful condition, human cells may bypass a checkpoint by acquisition of mutations, which would result in an accelerated cell growth and mutated MSCs (14). Therefore, MSCs with a low passage number for application might be more safe. MSCs are known to have an immune suppressive effect (17). MSCs can downregulate immune responses in vitro. MSCs suppress $\mathrm{T}$ cell proliferation in response to mitogenic or antigenic stimuli by releasing soluble factors including transforming growth factor- $\beta$ (TGF$\beta$ ) that may inhibit $\mathrm{T}$ cell proliferation (17). However, the in vivo relevance of the observations is still uncertain. In a recent study, MSCs were found to stimulate memory $\mathrm{T}$ cell responses in vivo following injection into MHC-mismatched, immune competent mice. Thus, MSCs are not intrinsically immune suppressive in vivo and may cause immune response following injection in immune competent recipients (18).

\section{Mechanism of cardiac tissue regeneration by BMSCs}

The mechanisms responsible for the beneficial effects of MSCs on cardiac function are still unclear. Several explanations have been proposed. The traditional theory is?that implanted bone marrow-derived MSCs may differentiate into cardiomyocytes and improve cardiac function. Differentiation of MSCs into cardiomyocytes has been demonstrated by culture of MSCs treated with either 5-azacytidine or a cocktail of growth factors (19). In a study, after MSCs were injected into infarcted myocardium in pigs, the injected MSCs expressed muscle-specific proteins, and the cardiac function and pathologic thinning were improved (20).

Another hypothesis is that injected MSCs may differentiate into endothelial cells and promote angiogenesis. This event may limit the extension of an infarction area and enhance repair processes of myocardium. Studies demonstrated that transplantation of MSCs enhanced angiogenesis and collateral formation (19). Implanted MSCs may promote angiogenesis by angiogenic factor secretion. MSCs release a major angiogenesis cytokine, vascular endothelial growth factor (VEGF), and can also produce SDF-1, which is critical for recruitment and entrapment of pro-angiogenic myeloid progenitor cells (21).

MSCs can also generate cardiomyocytes at a low frequency through cell fusion. In a study, no MSC-derived cardiomyocytes were observed in the infarction area, whereas very low levels of cardiomyocytes derived from fusion with MSCs were observed outside the infarction area (22). In another study, MSCs expressing both enhanced green fluorescent protein and cre-recombinase were injected into infarcted myocardium of Rosa mice that had cre-dependent $\beta$-galactosidase receptor. The study showed $\beta$-galactosidase activity in cell-injected tissue sections, suggesting fusion between injected MSCs and host cardiomyocytes (23). Phenotypic changes of MSCs into cardiomyocytes in coculture with cardiomyocytes, endothelial cells, or smooth muscle cells can result from cell fusion (24).

Cardiac regeneration by MSCs involves release of paracrine factors. The function of these factors is preventing apoptosis of cardiomyocytes, stimulating angiogenesis, helping matrix reorganization, and increasing MSC recruitment (24). MSCs can secrete a variety of angiogenic, antiapoptotic, and mitogenic factors, such as VEGF, hepatocyte growth factor, adrenomedullin, and insulin-like growth factor 1 (19). Therefore, the use of paracrine factors secreted from implanted MSCs for infarcted myocardium has the potential to reduce morbidity and mortality associated with cardiac remodeling. An animal study showed that injection of conditioned medium obtained from MSC culture exerted cytoprotective effects on the myocardium (25). The result suggest that isolation and administration of such factors at high concentrations or engineering MSCs for secretion of larger amounts of such factors can produce more significant protective effects.

MSC mobility to tissue damage region can be applied for repair of heart disease. A rat study demonstrated that MSCs in normal animals were localized to the bone marrow, while MSCs in bone marrow of rats with infarcted myocardium were found in the infarction zone (26). Ischemic myocardium may release cytokines and express adhesion molecules that facilitate the mobility of MSCs to infarcted myocardium. The mobilization factors include G-CSF, which promotes migration into the injured cardiomyocytes. Other factors are SDF-1 and matrix metalloproteinase. These factors induce and promote migration of MSCs into the infarcted myocardium. This strategy of endogenous mobilization has emerged as a viable therapeutic option for ischemic cardiovascular diseases. Patients with heart disease who may not tolerate the invasive procedures necessary for the harvest or transplantation of MSCs may be ideal candidates for this meth- 
od (24).

\section{Methods for differentiation of BMSCs into cardiomyocytes}

Soluble chemical factors can initiate signal transduction to regulate cell differentiation. In the embryonic stage, signaling molecules such as cytokines mediate embryonic specification and development of the heart and circulatory system. Differentiation of MSCs into cardiomyocyes can be induced by treating with 5-azacytidine or mixture of growth factors, including TGF- $\beta$, VEGF, insulin-like growth factor (IGF), and basis fibroblast growth factor (bFGF). Murine MSCs treated with 5-azacytidine can differentiate into beating cells with cardiac phenotype (27). Moreover, a recent study has investigated the ability of human MSCs to differentiate in vitro into cardiomyocytes after treatment with 5-azacytidine (28). It has reported that 5-azacytidine treatment of human MSCs resulted in the formation of tube-like cells that expressed cardiac markers, $\beta$-MHC, desmin, and $\alpha$-cardiac actin. In addition to 5-azacytidine, TGF- $\beta$ also stimulates upregulation of cardiac-related proteins. A study reported that TGF- $\beta 1$ stimulates the myogenic differentiation of CD117-positive HSCs by upregulating GATA-4 and NKx-2.5 expression, suggesting that TGF- $\beta 1$ induced the myogenic differentiation of CD117-positive cells (29). For vascular differentiation, human MSCs were profiled proteomically by using two-dimensional gel electrophoresis. The results showed differential expression of 30 proteins, including the decrease of gelsolin, an actin-binding protein that is a key regulator of actin filament assembly and disassembly, and the increase of smooth muscle $\alpha$-actin. VEGF was necessary for endothelial differentiation, and bFGF and IGF-1 enhanced endothelial colony formation (30). These studies suggest that chemical factors can regulate the differentiation of MSCs into cardiovascular cell types.

MSCs can differentiation into cardiomyocytes through coculture with cardiomyocytes. It suggests that direct cell-to-cell interaction is one of the microenvironmental factors for differentiation of MSCs into cardiomyocytes. A recent study demonstrated that MSCs can differentiate into cardiomyocytes when cocultivated with neonatal cardiomyocytes. The results of the study demonstrated that MSCs are capable of differentiating into cardiomyocytes when directly cocultured with neonatal cardiomyocytes, but not with adult cardiomyocytes or cultured with conditiond medium from neonatal cardiomyocytes (31). Another study showed that contraction of neighboring cardiomyocytes, as well as direct cell-to-cell contact, is necessary for transdifferentiation of skeletal muscle cells into cardiomyocytes (32).

Cell-extracellular matrix (ECM) interactions also play an important role in stem cell differentiation. Cardiomyocytes and cardiovascular endothelial cell produce ECMs, including structural proteins (collagen and elastin), adhesive proteins (laminin and fibronectin), anti-adhesive proteins (tenascin, thrombospondin, and osteopontin), and proteoglycans. Fibroblast-derived ECM demonstrates superior growth characteristics for in vitro cardiomyocyte culture, (29) suggesting that interaction between cells and ECM influences on cell growth. ECM also provides a temporary scaffold for the attachment, migration, and survival of transplanted cell. Following myocardial injury, cell migration and differentiation have been attributed partially to the ECM. The proper availability of biocompatible matrix would be of major importance in the stem cell differentiation into cardiomyocytes, and the optimal martix materials for stem cell differentiation may differ between the various types of stem cells (30).

When BMSCs are differentiated into cardiomyocytes, the cells express their unique and specific marker proteins in the cell membrane. For example, MCSs have expression of CD73, CD90 and CD105, and absence of CD34 and CD45 (6). Thus, cardiomyogenic differentiation of BMSCs can be recognized by their specific cell surface marker. In addition, differentiation of BMSCs into cardiomyocytes can be demonstrated by evidence of spontaneous beating and detection of cardiomyocyte-specific markers (19). The cardiac-specific markers include transcriptional factors, GATA-4 and Nkx-2.5, cytoskeletal proteins, $\beta$-myosin heavy chain $(\beta-M H C)$ and $\alpha$-cardiac actin, and cardiomyocyte-secreted hormones, atrial natriuretic peptide and brain natriuretic peptide (33). $\beta$-MHC and $\alpha$-cardiac actin are major markers to confirm cardiomyocytes differentiated from MSCs. A study showed that approximately $80 \%$ of cardiomyocytes differentiated from MSCs were positive for desmin, $\beta$-MHC, and $\alpha$-cardiac actin (34).

\section{Future directions}

Several studies have showed that, despite injecting a large number of stem cells, extremely small fraction of stem cells participate in regenerating cardiac tissue. Therefore, studies need to be conducted to develop the homing strategies of a sufficient number of stem cells to target organ. The strategies would help to deliver stem cells through intravenous injection, instead of injection in- 
to heart. Molecular biological mechanisms for regeneration of injured myocardium after postinfaction have to be studied. Clear understanding on signal pathways to stimulate proliferation of stem cells, homing of cardiomyocytes, and differentiation to cardiomyocyes and endothelial cells would maximize applications of MSCs to regenerate cardiac tissue.

\section{Acknowledgement}

This work was supported by a grant from the Korea Health 21 R\&D project, ministry of Health \& Welfare, Republic of Korea (grant no. A080467).

\section{Potential Conflict of Interest}

The authors have no conflicting financial interest.

\section{References}

1. Korean statistical information service (http://www.kosis.kr/ domestic/theme/do01_index.jsp)

2. Yuyama ET, Matsubara H, Murohara T, Ikeda U, Shintani S, Masaki H, Amano K, Kishimoto Y, Yoshimoto K, Akashi $\mathrm{H}$, Shimada K, Iwasaka T, Imaizumi T. Therapeutic angiogenesis for patients with limb ischaemia by autologous transplantation of bone marrow cells: a pilot study and a randomised controlled trial. Lancet 2002;360:427-435

3. Orlic D, Kajstura J, Chimenti S, Jakoniuk I, Anderson SM, Li B, Pickel J, McKay R, Nadal-Ginard B, Bodine DM, Leri A, Anversa P. Bone marrow cells regenerate infarcted myocardium. Int J Hematol 2007;86:17-21

4. Tomita S, Ren KL, Richard DW, Donald AG, Mickle, Kim EJ, Sakai T, Jia JQ. Autologous transplantation of bone marrow sells improves damaged heart function. Circulation 1999;100[supplII]:II-247-II-256

5. Cottler-Fox MH, Lapidot T, Petit I, Kollet O, DiPersio JF, Link D, Devine S. Stem cell mobilization. Hematology Am Soc Hematol Educ Program 2003:419-437

6. Togel F, Westenfelder C. Adult bone marrow?derived stem cells for organ regeneration and repair. Dev Dyn 2007;236: 3321-3331

7. Ince H, Petzsch M, Kleine HD, Eckard H, Rehders T, Burska D, Kische S, Freund M, Nienaber CA. Prevention of left ventricular remodeling with granulocyte colony-stimulating factor after acute myocardial infarction: final 1-year results of the front-integrated revascularization and stem cell liberation in evolving acute myocardial infarction by granulocyte colony-stimulating factor (FIRSTLINE-AMI) trial. Circulation 2005;112:I-73-I-80

8. Seiler C, Pohl T, Wustmann K, Hutter D, Nicolet PA, Windecker S, Eberli FR, Meier B. Colony-stimulating factor in patients with coronary artery disease: A promotion of collateral growth by granulocyte-macrophage randomized, double-blind, placebo-controlled study. Circulation 2001;104:
2012-2017

9. Wollert K, Meyer G, Lotz J, Lichtenberg SR, Lippolt P, Breidenbach C, Fichtner S, Korte T, Hornig B, Messinger D. Intracoronary autologous bone-marrow cell transfer after myocardial infarction: the BOOST randomised controlled clinical trial. Lancet 2004;364:141-148

10. Schächinger V, Erbs S, Elsässer A, Haberbosch W, Hambrecht R, Hölschermann H, Yu J, Corti R, Mathey DG, Hamm CW, Süselbeck T, Assmus B, Tonn T, Dimmeler S, Zeiher AM. Intracoronary bone marrow?derived progenitor cells in acute myocardial infarction. N Engl J Med 2006;355: 1210-1221

11. Breitbach M, Bostani T, Roell W, Xia Y, Dewald O, Nygren JM, Fries JWU, Tiemann K, Bohlen H, Hescheler J, Welz A, Bloch W, Jacobsen SEW, Fleischmann BK. Potential risks of bone marrow cell transplantation into infarcted hearts. Blood 2007;110:1362-1369

12. Yoon YS, Park JS, Tkebuchava T, Luedeman C, Losordo DW. Unexpected severe calcification after transplantation of bone marrow cells in acute myocardial infarction. Circulation 2004;109:3154-3157

13. Kunter U, Rong S, Boor P, Eitner F, Newen GM, Djuric Z, Roeyen CR, Konieczny A, Ostendorf T, Villa L, Popovska MM, Kerjaschki D, Floege J. Mesenchymal stem cells prevent progressive experimental renal failure but maldifferentiate into glomerular adipocytes. J Am Soc Nephrol 2007; 18:1754-1764

14. Atsma DE, Fibbe WE, Rabelink TJ. Opportunities and challenges for mesenchymal stem cell-mediated heart repair. Curr Opin Lipidol 2007;18:645-649

15. Rubio D, Castro JG, Martín MC, Fuente R, Cigudosa JC, Lloyd AC, Bernad A. Spontaneous human adult stem cell transformation. Cancer Res 2005;65:3035-3039

16. Tolar J, Nauta AJ, OsbornMJ, Mortari AP. Sarcoma derived from cultured mesenchymal stem cells. Stem Cells 2007;25: 371-379

17. Tyndall A, Walker UA, Cope A, Dazzi F, Bari CD, Fibbe W, Guiducci S, Jones S, Jorgensen C, Blanc KL, Luyten F, McGonagle D, Martin I, Tyndall CB, Pennesi G, Pistoia V, Pitzalis C, Uccelli A, Wulffraat N, Feldmann M. Immunomodulatory properties of mesenchymal stem cells: a review based on an interdisciplinary meeting held at the Kennedy Institute of Rheumatology Division, London, UK, 31 October 2005. Arthritis Res Ther 2007;9:301

18. Nauta AJ, Westerhuis G, Kruisselbrink AB, Lurvink FGA, Willemze R, Fibbe WE. Donor-derived mesenchymal stem cells are immunogenic in an allogeneic host and stimulate donor graft rejection in a nonmyeloablative setting. Blood 2006; 108:2114-2120

19. Ohnishi S, Ohgushi H, Kitamura S, Nagaya N. Mesenchymal stem cells for the treatment of heart failure. Int J Hematol 2007;86:17-21

20. Shake JG, Gruber PJ, Baumgartner WA, Senechal G, Meyers J, Redmond JM, Pittenger MF, Martin BJ. Mesenchymal stem cell implantation in a swine myocardial infarct model: engraftment and functional effects. Ann Thorac Surg 
2002;73:1919-1925

21. Ceradini DJ, Kulkarni AR, Callaghan MJ, Tepper OM, Bastidas N, Kleinman ME, Capla JM, Galiano RD, Levine JP, Gurtner GC. Progenitor cell trafficking is regulated by hypoxic gradients through HIF-1 induction of SDF-1. Nat Med 2004;10:858-864

22. Nygren JM, Jovinge S, Breitbach M, Sawen P, Roll W, Hescheler J, Taneera J, Fleischmann BK, Jacobsen SE. Bone marrow-derived hematopoietic cells generate cardiomyocytes at a low frequency through cell fusion, but not differentiation. Nat Med 2004;10:494-501

23. Noiseux N, Gnecchi M, Ilasaca ML, Zhang L, Solomon SD, Deb A, Dzau VJ, Pratt RE. Mesenchymal stem cells overexpressing Akt dramatically repair infarcted myocardium and improve cardiac function despite infrequent cellular fusion or differentiation. Mol Ther 2006;14:840-850

24. Wang XJ, Li QP. The roles of mesenchymal stem cells (MSCs) therapy in ischemic heart diseases. Biochem Biophy Res Comm 2007;359:189-193

25. Gnecchi M, He H, Liang OD, Melo LG, Morello F, Mu H, Noiseux N, Zhang L, Pratt RE, Ingwall JS, Dzau VJ. Paracrine action accounts for marked protection of ischemic heart by Akt-modified mesenchymal stem cells. Nat Med 2005;11:367-368

26. Jackson KA, Majka SM, Wang H, Pocius J, Hartley CJ. Regeneration of ischemic cardiac muscle and vascular endothelium by adult stem cells. J Clin Invest 2002;107:13951402

27. Makino S, Fukuda K, Miyoshi S, Konishi F, Kodama H, Pan J, Sano M, Takahashi T, Hori S, Abe H, Hata J, Umezawa A, Ogawa S. Cardiomyocytes can be generated from marrow stromal cells in vitro. J Clin Invest 1999;103:
697-705

28. Antonitsis P, Papagiannaki EI, Kaidoglou A, Papakonstantinou C. In vitro cardiomyogenic differentiation of adult human bone marrow mesenchymal stem cells. The role of 5-azacytidine. Interact Cardiovasc Thorac Surg 2007;6:593597

29. VanWinkle WB, Snuggs MB, Buja LM. Cardiogel: a biosynthetic extracellular matrix for cardiomyocyte culture. In Vitro Cell Dev Biol Anim 1996;32:478-485

30. Huang NF, Lee RJ, Li S. Chemical and physical regulation of stem cells and progenitor cells: Potential for cardiovascular tissue engineering. Tissue Eng 2007;13:18091823

31. Yoon JY, Shim WJ, Ro YM, Lim DS. Transdifferentiation of mesenchymal stem cells into cardiomyocytes by direct cell-to-cell contact with neonatal cardiomyocyte but not adult cardiomyocytes. Ann Hematol 2005;84:715-721

32. Iijima $Y$, Nagai $T$, Mizukami $M$, Matsuura $K$, Ogura $T$, Wada H, Toko H, Akazawa H, Takano H, Nakaya H, Komuro I. Beating is necessary for transdifferentiation of skeletal muscle-derived cells into cardiomyocytes. FASEB J 2003;17:1361-1363

33. Itescu S, Schuster MD, Kocher AA. New directions in strategies using cell therapy for heart disease. J Mol Med 2003; 81:288-296

34. Xu W, Zhang X, Qian H, Zhu W, Sun X, Hu J, Zhou H, Chen YC. Mesenchymal stem cells from adult human bone marrow differentiates into a cardiomyocyte phenotype in vitro. Exp Biol Med 2004;229:623-631

35. Kim HS. Stem cell research for cardiovascular regeneration. Mol Cell Biol News 2005;17:31-40 